\title{
Inpatient palliative chemotherapy is associated with high mortality and aggressive end-of-life care in patients with advanced solid tumors and poor performance status
}

Vitor Fiorin de Vasconcellos ${ }^{1 *}$, Renata RCC Bonadio ${ }^{1}$ (D), Guilherme Avanço ${ }^{1}$, Marcelo Vailati Negrão ${ }^{1,2}$ (D) and Rachel Pimenta Riechelmann ${ }^{3}$ (D)

\begin{abstract}
Background: The benefit of palliative chemotherapy (PC) in patients with advanced solid tumors and poor performance status (ECOG-PS) has not been prospectively validated, which makes treatment decision challenging. We aimed to evaluate the overall survival, factors associated with early mortality, and adoption of additional procedures in hospitalized patients with advanced cancer and poor ECOG-PS treated with PC.

Methods: We analyzed a retrospective cohort of patients with advanced cancer treated with PC during hospitalization at an academic cancer center in Brazil from 2014 to 2016. Eligibility criteria included: ECOG-PS 3-4 and start of first-line PC; or ECOG-PS $\geq 2$ and start of second or subsequent lines. Primary endpoint was 30-day survival from start of PC. Kaplan-Meier method was used for survival estimates and Cox regression for factors associated with 30-day mortality.

Results: Two hundred twenty-eight patients were eligible. 21.9, 66.7 and 11.4\% of patients had ECOG-PS 2, 3 and 4, respectively. 49.6\% had gastrointestinal tumors. Median follow-up was 49 days (range 1-507). 98.2\% of patients had died, 32\% during the index hospitalization. The 30-day and 60-day survival rates were 55.7 and 38.5\%, respectively. 30\% of patients were admitted to the intensive care unit. In a multivariable analysis, ECOG-PS 3/4 (HR 2.01; $P=0.016$ ), hypercalcemia (HR 2.19; $P=0.005)$, and elevated bilirubin (HR 3.17; $P<0.001)$ were significantly associated with 30-day mortality.
\end{abstract}

Conclusions: Patients with advanced cancer and poor ECOG-PS had short survival after treatment with inpatient PC. Inpatient PC was associated with aggressive end-of-life care. Prognostic markers such as ECOG-PS, hypercalcemia and elevated bilirubin can contribute to the decision-making process for these patients.

Keywords: Palliative, Chemotherapy, Metastasis, Cancer, Hospitalization, Medical futility, Prognosis, Retrospective study, Survival rate, Latin America

\footnotetext{
* Correspondence: vitor.vasconcellos@gmail.com

${ }^{1}$ Medical Oncology Department, Instituto do Cancer do Estado de São Paulo

(ICESP), Avenida Dr. Arnaldo, 251, Cerqueira César, São Paulo 01246-000,

Brazil

Full list of author information is available at the end of the article
}

(C) The Author(s). 2019 Open Access This article is distributed under the terms of the Creative Commons Attribution 4.0 International License (http://creativecommons.org/licenses/by/4.0/), which permits unrestricted use, distribution, and reproduction in any medium, provided you give appropriate credit to the original author(s) and the source, provide a link to the Creative Commons license, and indicate if changes were made. The Creative Commons Public Domain Dedication waiver (http://creativecommons.org/publicdomain/zero/1.0/) applies to the data made available in this article, unless otherwise stated. 


\section{Background}

Palliative chemotherapy $(\mathrm{PC})$ is a non-curative treatment given to cancer patients diagnosed with unresectable or metastatic disease to improve patients' symptomatic control and/or quality of life, or to prolong survival $[1,2]$. However, these potential benefits of treatment must be weighed against the risks for potentially serious and life-threatening adverse events such as neutropenic fever, major bleeding, renal failure, colitis, hepatic dysfunction, among others [3].

Due to the lack of robust predictive biomarkers of benefit from conventional cytotoxic chemotherapy, general prognostic markers such as performance status and patient comorbidities are usually used to select patients that are eligible for this type of therapy [4]. One of the well-established methods to assess cancer patients' performance status (PS) is the Eastern Cooperative Oncology Group Performance Status (ECOG-PS), an ordinal 5-points scale with increasing scores indicating more severe disability [1].

The American Cancer Society of Clinical Oncology (ASCO) previously published recommendations against the use of cancer-directed therapy for patients with solid tumors and poor ECOG-PS (i.e., ECOG-PS $\geq 3$ defined as "capable of only limited self-care, confined to bed or chair more than $50 \%$ of walking hours") [5]. This was based on the limited inclusion of these patients in clinical trials as well as observational studies correlating poor ECOG-PS to lower response rate, poor treatment tolerance and shorter overall survival [5-7]. Additionally, this guideline considers a 30-day mortality rate of 20-50\% to be excessive.

On the other hand, a previous retrospective analysis of 240 consecutive patients conducted in our institution showed that $48.6 \%$ of patients with metastatic colorectal cancer with an ECOG-PS 3-4 achieved some clinical benefit in terms of symptom improvement, experienced a low rate of serious adverse events (21.7\%) and overall survival was longer compared to patients treated with best supportive care (BSC) (OS 6.8 versus 2.3 months, respectively) [8].

Another retrospective analysis of 199 patients with advanced cancer who started PC while hospitalized (breast cancer: $23 \%$; small cell lung cancer: $22 \%$; non-small cell lung cancer: $16 \%)$, showed a hospital discharge rate of $77 \%$ and $72 \%$ of patients were able to receive subsequent cycles of chemotherapy [9].

Therefore, a better understanding of the consequences of the use of $\mathrm{PC}$ in those patients is required to avoid unnecessary or potentially harmful therapies and misguided decisions in end-of-life care [10-13]. Identifying the factors associated with a higher risk of early mortality would contribute to substantiate decisions regarding active treatment or best support of care.
In this study, we aimed to evaluate the outcomes of patients with advanced cancer and poor ECOG-PS treated with inpatient PC, including the overall survival, factors associated with early mortality, and the rate of invasive procedures performed. We hypothesized that inpatient PC in this scenario would be associated with short overall survival, indirectly compared with ECOG-PS 0 or 1 cancer patients, and aggressive medical care near the end of life.

\section{Methods}

\section{Patient accrual and data collection}

This was a retrospective study of consecutive hospitalized patients with advanced and incurable solid tumors and poor ECOG-PS who were treated with PC during hospitalization at a large academic and public cancer center (Instituto do Câncer do Estado de São Paulo ICESP), between January 2014 and September 2016.

Advanced and incurable solid tumors were defined as recurrent or metastatic tumors for which no treatment with curative intent was available. Therapies with curative intent include complete surgical resection, definitive chemoradiation, or systemic chemotherapy for germ cell tumors. We defined poor performance status as ECOG-PS $\geq 2$ on the first day of treatment with PC. ECOG-PS was available for all patients in the institution per electronic patient chart. The cancer center where the study took place, ICESP, is one of the largest cancer centers of Latin America, with approximately 10,000 new cancer patients per year and 499 beds for patients' hospitalization.

Patients were included if they had histologically confirmed advanced solid tumors, and had ECOG-PS 3-4 at the time of starting frontline PC, or had ECOG-PS $\geq 2$ at the time of starting second or later lines of chemotherapy. The rationality for these inclusion criteria was to represent poor ECOG-PS patients that are usually not included in clinical trials. Patients with ECOG-PS 2 receiving first-line chemotherapy were not included since this is often considered a standard of care. Solid tumors were considered all non-hematological malignancies.

Exclusion criteria included highly chemo-sensitive histologies (germ cell tumors, ovarian serous adenocarcinoma, and small cell lung cancer) and primary tumors of the central nervous system (CNS). Patients with primary CNS tumors were excluded because they frequently present poor ECOG-PS due to neurologic deficits even at disease diagnosis. To obtain our sample, we reviewed data from all consecutive patients that received chemotherapy during hospitalization according to the hospital records and included those that met eligibility criteria. The medical records were available at the cancer center (ICESP) database. Accessing the database required a permission, which was obtained with the Research Center of ICESP. 
Data was collected from the electronic medical records and included: age, gender, primary tumor site, clinical stage (based on imaging studies), number of metastatic sites, main symptom(s) at hospitalization, line of chemotherapy and regimen (single agent versus combination), Charlson Comorbidity Index score, and body mass index. Charlson Comorbidity Index is a scale used to predict mortality based on patient comorbidities [14]. Main symptom(s) at hospitalization were the symptoms related to the reason of hospitalization (e.g.: abdominal pain and obstipation in case of malignant bowel obstruction). Nausea, vomiting, diarrhea, obstipation and abdominal pain were grouped as gastrointestinal symptoms. Neurologic symptoms included headache, seizure, focal neurologic deficits, and altered level of consciousness.

Laboratory tests at admission were reviewed to determine the hemoglobin $(\mathrm{Hb})$ levels, total leukocyte and lymphocyte count, creatinine $(\mathrm{Cr})$, alanine aminotransferase (ALT), aspartate aminotransferase (AST), total bilirubin $(\mathrm{Bb})$, and calcium levels. Data on additional procedures used during hospitalization and place of death were also collected. Additional procedures recorded were blood transfusions, palliative radiotherapy, surgical procedures and/or admission to the intensive care unit (ICU).

The primary endpoint of the study was 30-day survival rate from the start of the first inpatient chemotherapy cycle. Secondary endpoints included median survival, 60-day survival rate from the start of the first inpatient chemotherapy cycle, prognostic factors associated with survival, rate of additional procedures performed, and hospital discharge rate after starting chemotherapy.

The prognostic factors evaluated were sex, age, primary tumor site, number of sites of metastases (less than or equal to 2 vs greater than 2), main symptom that led to hospitalization, ECOG-PS (3-4 vs 2), body mass index and Charlson index ( $\leq 6 \mathrm{vs}>6$ points), and laboratory abnormalities. The cutoff value for the number of sites of metastases was chosen based on previous studies suggesting that the presence of more than 2 metastatic sites is associated with shorter overall survival $[15,16]$. As for the Charlson index, we decided to compare $\leq 6$ vs $>6$ points because most patients would have a score of at least 6 due to the diagnosis of a metastatic solid tumor.

The laboratory tests were categorized according to the presence or absence of the following laboratory abnormalities: anemia (defined by $\mathrm{Hb}<10 \mathrm{~g} / \mathrm{dL}$ ), leukocytosis (leukocytes $\geq 10.000$ per $\mathrm{mm}^{3}$ ), lymphopenia (lymphocytes $\leq 1500$ per $\mathrm{mm}^{3}$ ), hypercalcemia (defined by ionized calcium $\geq 5.3 \mathrm{mEq} / \mathrm{L}$ or total corrected calcium $\geq 10.2 \mathrm{mg} / \mathrm{dL}$ ), elevated liver function tests (LFT) (defined by AST or ALT $\geq 2.5$ times upper limit of normal), renal impairment (defined by $\mathrm{Cr} \geq 1.5 \mathrm{mg} / \mathrm{dL}$ ), and elevated bilirubin (defined by total $\mathrm{Bb} \geq 1.5 \mathrm{mg} / \mathrm{dL}$ ). Both clinical and laboratory variables were categorized based on clinical relevance for interpretation of the results in the clinical setting. Information on the clinical variables was available for all patients since it is systematically registered in electronic records during hospitalization at ICESP. For the laboratory tests, the median value was used for missing value imputation. The rates of missing data for the laboratory variables ranged from 0 to $17 \%$.

\section{Statistical analysis}

Descriptive statistics were used to summarize patient characteristics. The absolute and relative frequencies of clinical and demographic data were tabulated. Qualitative variables were presented as proportions and quantitative variables were presented as median and respective ranges.

Survival analysis was performed using the Kaplan-Meier method. Factors associated with 30-day mortality were evaluated with univariable and multivariable analysis by using Cox regression. Prognostic factors with $P \leq 0.10$ in univariable analysis and with no association between each other were included in the multivariable model. The association between categorical variables was evaluated by using $\mathrm{X}^{2}$ test. A two-tailed $P$ value $\leq 0.05$ was considered statistically significant. Statistical analyses were performed using Stata software, version 14 (StataCorp, Texas, USA).

\section{Results}

\section{Patients' characteristics}

A total of 979 patients with solid tumors received PC during hospitalization between 2014 and 2016. Of these, 228 consecutive patients fulfilled the eligibility criteria and were included in the analysis. The CONSORT diagram is presented in Fig. 1.

Median age was 56 years (range 21-79). The majority of patients were female $(58 \%)$ and chemotherapy-naïve (66\%). The most common primary tumor sites were gastrointestinal (49.6\%) and breast (18.4\%). The proportions of ECOG-PS 2, 3 and 4 were 21.9, 66.7, and 11.4\%, respectively. The majority of patients had metastatic disease at presentation $(N=223 ; 97.8 \%)$, and only 5 patients $(2.2 \%)$ had a locally advanced disease not amenable for treatment with curative intent. Patients were predominantly treated with a combination chemotherapy regimen $(N=173 ; 76 \%)$.

Seventy-one patients (31.1\%) were hospitalized because of gastrointestinal symptoms, including 40 patients (17.5\%) with malignant bowel obstruction $(N=40 ; 17.5 \%)$. Other common causes of admission included dyspnea, pain, and sepsis.

Patient characteristics are summarized in Table 1.

\section{Outcomes}

Median follow-up was 49 days (range 1-507 days). Two hundred and twenty-four patients had died (98.2\%), and 


\section{Patients submitted to inpatient chemotherapy}

751 Exclusions

165 Elective hospitalizations for CT infusion

161 ECOG-PS 2 treated with first line CT

103 ECOG-PS 0-1

76 Small cell lung cancer

$71 \mathrm{CT}$ initiated as outpatient treatment

50 Non-advanced disease/ curative treatment

51 Ovarian cancer

25 Germ cell tumor

18 Unavailable data

11 Loss to follow-up

8 More than one primary malignancy

7 Central nervous system malignancy

5 Intraperitoneal CT

228 Patients included

Fig. 1 CONSORT diagram

median overall survival was 38.5 days. 30-day and 60-day survival rates were 55.7 and $38.5 \%$, respectively. Seventy-three patients (32\%) died during the same admission in which PC was started. Thirty-one patients (13.8\%) died in the intensive care unit (ICU), twenty-seven patients (12\%) died in an inpatient hospice facility and two patients (0.8\%) died at home.

Median duration of index hospitalization was 16 days (range 2-87 days). Eighty-six patients (37\%) required invasive procedures during the index hospitalization, which included 68 patients $(30 \%)$ that required intensive care unit admission and 37 (16\%) that underwent surgical procedures. One hundred and three patients (45\%) received blood transfusions, and 22 patients $(9.6 \%)$ received palliative radiotherapy. Approximately $68 \%$ of patients $(N=155)$ were discharged from the hospital after receiving PC, and 100 patients $(43.8 \%)$ received at least one more cycle of PC as an outpatient after the index hospitalization. Outcomes of interest are summarized in Table 2.

\section{Factors associated with 30-day mortality}

In univariable analysis, 30-day mortality was positively correlated with presence of gastrointestinal symptoms at admission (harzard ratio [HR]: 2.04, 95\% confidence interval [CI] 1.07-3.88, p 0.029), ECOG-PS (3-4 vs 2) (HR 2.05, 95\% CI 1.17-3.62, $P=0.012$ ), hypercalcemia (HR 2.09, 95\% CI 1.20-3.63, $P=0.008$ ), elevated LFTs (HR 1.84, 95\% CI 1.17-2.90, $P=0.008$ ) and elevated bilirubin (HR 3.07, 95\% CI 1.94-4.84, $P=<0.001$ ).
Among these variables, only ECOG-PS, hypercalcemia, and elevated bilirubin met inclusion criteria for the multivariable model. Gastrointestinal symptoms and elevated LFTs were not included because they were positively correlated with elevated bilirubin $\left(\chi^{2} \quad P=0.003\right.$; and $\chi^{2}$ $P<0.001$, respectively). In the multivariable analysis, three prognostic factors were independently associated with 30-day mortality: ECOG-PS (3-4 vs 2) (HR 2.01, 95\% CI 1.14-3.53, $P=0.016$ ), hypercalcemia (HR 2.19, 95\% CI 1.26-3.80, $P=0.041$ ), and elevated bilirubin (HR 3.17, 95\% CI 2.00-5.01, $P<0.001)$.

The results for the univariable and multivariable analyses are summarized in Tables 3 and 4, respectively.

\section{Discussion}

Our results showed that hospitalized patients with advanced cancers (with the exclusion of highly chemo-sensitive histologies and primary CNS tumors) and poor performance status had a low survival rate after receiving PC. Median OS was 38.5 days, and 30 - and 60 -day survival rates were 55.7 and $38.5 \%$, respectively, highlighting that these patients had very poor outcomes regardless if they had initiated active cancer treatment or, in some cases, had received invasive life support interventions (e.g., ICU admission and surgical procedures).

Previous phase II/III clinical trials and meta-analysis have shown that cytotoxic chemotherapy improved survival and quality of life compared to BSC alone across different primary solid tumors [17-19]. However, these results cannot be extrapolated to indicate inpatient 
Table 1 Patient characteristics

\begin{tabular}{lll}
\hline & N & $\%$ \\
\hline Male gender & 95 & 41.7 \\
Age: median (range) & $56(21-79)$ & \\
Primary tumor site & & \\
Gastrointestinal & 113 & 49.6 \\
Colorectal & 45 & 19.7 \\
Gastric & 38 & 16.6 \\
Pancreatic/Biliary & 13 & 5.7 \\
Others & 17 & 7.4 \\
Breast & 42 & 18.4 \\
NSCLC & 25 & 11 \\
Sarcoma & 13 & 5.7 \\
Gynecologic & 11 & 4.8 \\
Genitourinary & 9 & 3.9 \\
Head and Neck & 7 & 3.1 \\
Skin (squamous cell carcinoma) & 5 & 2.2 \\
Unknown primary & 3 & 1.3
\end{tabular}

Number of metastatic sites

$$
\leq 2
$$$$
>2
$$

Main symptom at hospitalization

Pain

Dyspnea

Infection-related symptoms

Bleeding/ Symptomatic anemia

Gastrointestinal symptoms

Neurologic symptoms

Fatigue

Chemotherapy line

First line

Second line or greater

Chemotherapy regimen

Single agent

Combination regimen

ECOG-PS

$\begin{array}{ll}2 & 50 \\ 3 & 15 \\ 4 & 26 \\ \text { Anemia }^{1} & 11 \\ \text { Leukocytosis }^{2} & 85 \\ \text { Lymphopenia }^{3} & 86 \\ \text { Hypercalcemia }^{4} & 23 \\ \text { Renal impairment }^{5} & 21 \\ \text { Elevated liver function tests }^{6} & 43 \\ \text { Total bilirubin elevation }^{7} & 33\end{array}$

Table 1 Patient characteristics (Continued)

\begin{tabular}{lll}
\hline BMl & N & $\%$ \\
Underweight $^{8}$ & 32 & \\
Normal $^{9}$ & 123 & 14 \\
Overweight $^{10}$ & 37 & 53.9 \\
Obesity $^{11}$ & 36 & 16.2 \\
Charlson Index $>6^{10}$ & 63 & 15.8 \\
\hline
\end{tabular}

Abbreviations: NSCLC non-small cell lung cancer, ECOG-PS Eastern Cooperative Oncology Group Performance Status, BMI body mass index

${ }^{1}$ Hemoglobin $<10 \mathrm{~g} / \mathrm{dL}^{2}{ }^{2}$ White Blood Cell count $\geq 10.000 / \mathrm{mm}^{3}$; ${ }^{3}$ Lymphocytes count $\leq 1500 / \mathrm{mm}^{3} ;{ }^{4}$ Ionized Calcium $\geq 5.3 \mathrm{mEq} / \mathrm{L}$ or Total Corrected Calcium $\geq 10.2 \mathrm{mg} / \mathrm{dL}^{5}{ }^{5}$ Creatinine $\geq 1.5 \mathrm{mg} / \mathrm{dL}^{6}{ }^{6}$ Aspartate Aminotransferase or Alanine Aminotransferase $\geq 2.5$ times upper limit of normal; ${ }^{7}$ Total Bilirubin $\geq 1.5 \mathrm{mg} / \mathrm{dL}$; ${ }^{8} \mathrm{BMI}<18.5$; ${ }^{9} \mathrm{BMI} 18.5$ to 24.9 ; ${ }^{10} \mathrm{BMI} 25$ to $29.9 ;{ }^{11} \mathrm{BMI} \geq 30$

PC to poor performance status patients because this population is often excluded or underrepresented in clinical trials [20].

A Spanish single-center study with eligibility criteria similar to ours analyzed 92 patients and showed that mOS was 33 days from the last course of chemotherapy [21]. A Canadian single-center cohort with 199 patients reported mOS of 4.5 months from the date of starting chemotherapy in the inpatient setting [22]. One possible explanation for the heterogeneous findings in Canada is that $22 \%$ of their patients had small-cell lung cancer, a recognized highly chemo-sensitive histology that was excluded from our analysis. Our results were consistent with the majority of literature that shows a short survival for poor performance status patients after receiving inpatient $\mathrm{PC}$.

Table 2 Summary of the outcomes of interest

\begin{tabular}{ll}
\hline Outcome & $N=228$ \\
\hline Deaths - N (\%) & $224(98.2)$ \\
30-day survival rate - \% & 55.7 \\
60-day survival rate - \% & 38.5 \\
Median overall survival - days & 38.5 \\
Death during the index hospitalization - N (\%) & $73(32)$ \\
Place of death - N (\%) & \\
Intensive care unit (ICU) & $31(13.8)$ \\
Hospital (except ICU) & $164(73.2)$ \\
Inpatient hospice facility & $27(12)$ \\
Home & $2(0.8)$ \\
Additional procedures - N (\%) & \\
ICU admission & $68(30)$ \\
Surgical procedures & $37(16)$ \\
Blood transfusion & $103(45)$ \\
Palliative radiotherapy & $22(9.6)$ \\
\hline
\end{tabular}

Abbreviations: ICU intensive care unit 
Table 3 Univariable analyses of factors associated with 30-day mortality

\begin{tabular}{|c|c|c|}
\hline & $\mathrm{HR}(95 \% \mathrm{Cl})$ & $P$ value \\
\hline Female gender & $1.25(0.83-1.87)$ & 0.270 \\
\hline Age & $1.00(0.98-1.01)$ & 0.898 \\
\hline \multicolumn{3}{|l|}{ Primary tumor site } \\
\hline Cutaneous squamous-cell carcinoma & (reference) & \\
\hline Gastrointestinal & $1.32(0.32-5.44)$ & 0.693 \\
\hline Breast & $1.15(0.26-5.01)$ & 0.845 \\
\hline Head and Neck & $2.75(0.53-14.23)$ & 0.226 \\
\hline Genitourinary & $0.52(0.07-3.69)$ & 0.515 \\
\hline Gynecologic & $1.00(0.18-5.48)$ & 0.996 \\
\hline Lung & $0.92(0.19-4.25)$ & 0.915 \\
\hline Sarcoma & $0.87(0.16-4.49)$ & 0.871 \\
\hline Unknown primary & $0.90(0.08-9.94)$ & 0.933 \\
\hline Number of metastatic sites ( $>2$ vs $\leq 2$ ) & $0.91(0.66-1.35)$ & 0.663 \\
\hline \multicolumn{3}{|l|}{ Main symptom at hospitalization } \\
\hline Pain & (reference) & \\
\hline Dyspnea & $1.04(0.50-2.17)$ & 0.896 \\
\hline Infection-related symptoms & $1.14(0.49-2.64)$ & 0.753 \\
\hline Bleeding/ Symptomatic anemia & $0.53(0.15-1.90)$ & 0.336 \\
\hline Gastrointestinal symptoms & $2.04(1.07-3.88)$ & 0.029 \\
\hline Neurologic symptoms & $1.79(0.67-4.78)$ & 0.243 \\
\hline Fatigue & $1.79(0.77-4.16)$ & 0.171 \\
\hline ECOG-PS (3-4 vs 2) & $2.05(1.17-3.62)$ & 0.012 \\
\hline Anemia (yes vs no) & $1.05(0.71-1.55)$ & 0.792 \\
\hline Leukocytosis (yes vs no) & $1.20(0.80-1.79)$ & 0.364 \\
\hline Lymphopenia (yes vs no) & $1.07(0.72-1.60)$ & 0.710 \\
\hline Hypercalcemia (yes vs no) & $2.09(1.20-3.63)$ & 0.008 \\
\hline Renal impairment (yes vs no) & $1.20(0.62-2.31)$ & 0.573 \\
\hline Liver enzymes elevation (yes vs no) & $1.84(1.17-2.90)$ & 0.008 \\
\hline Total bilirubin elevation (yes vs no) & $3.07(1.94-4.84)$ & $<0.001$ \\
\hline \multicolumn{3}{|l|}{ Body mass index } \\
\hline Underweight & (reference) & \\
\hline Normal & $1.07(0.58-1.97)$ & 0.810 \\
\hline Overweight & $1.09(0.52-2.26)$ & 0.817 \\
\hline Obesity & $1.25(0.61-2.59)$ & 0.531 \\
\hline Charlson Index $>6$ & $1.27(0.83-1.94)$ & 0.253 \\
\hline
\end{tabular}

Abbreviations: ECOG-PS Eastern Cooperative Oncology Group Performance Status, $H R$ hazard ratio, $\mathrm{Cl}$ confidence interval

'Univariable Cox regression

Importantly, the use of chemotherapy near the end of life has been associated with more invasive procedures near death, including ICU admissions, delays in hospice referrals, and increased treatment costs [23-25]. In a prospective cohort study evaluating 386 terminally ill cancer patients, $11 \%$ of the patients that received PC died in the ICU in comparison with $2 \%$ of those who did
Table 4 Multivariable analyses of factors associated with 30-day mortality

\begin{tabular}{|c|c|c|}
\hline & Adjusted HR (95\% Cl) & $P$ value \\
\hline ECOG-PS (3-4 vs 2) & $2.01(1.14-3.53)$ & 0.016 \\
\hline Hypercalcemia (yes vs no) & $2.19(1.26-3.80)$ & 0.005 \\
\hline Total bilirubin elevation (yes vs no) & $3.17(2.00-5.01)$ & $<0.001$ \\
\hline
\end{tabular}

not receive PC $(P=0.02)$ [25]. In our cohort, $37 \%$ of patients underwent invasive procedures, $30 \%$ underwent ICU admission, and $13.8 \%$ died in the ICU. These findings raised concern for futility and potential harm in end-of-life care (e.g. death in ICU) when adopting aggressive medical interventions in patients with advanced disease and poor ECOG-PS. In addition, limited resources available in the Brazilian public health system raise yet another reason to avoid not cost-effective and potentially futile interventions.

A combination of several factors has been described as a possible reason for why medical oncologists offer PC to poor performance status patients. These factors include: (i) physicians overestimate prognosis of metastatic cancer patients [26]; (ii) limited evidenced-based treatment recommendations in this scenario [27]; (iii) patients' and families' expectations to receive anti-cancer therapy [23]; (iv) young or middle-aged patients [28]; (v) absence of palliative care team participating in the patients care [29]; and (vi) care at an academic/ teaching hospital [24]. Our cohort was composed mainly of treatment naïve patients who were admitted in an academic cancer center due to symptoms related to advanced solid tumor disease. These characteristics could, at least in part, explain the high rates of inpatient $\mathrm{PC}$ and invasive procedures.

Our findings suggest an over-prescription of $\mathrm{PC}$ in this population because almost half of the patients (44.3\%) died within 30 days of starting treatment. As mentioned previously, ASCO's recommendation supports that 20-50\% 30-day mortality rate after starting chemotherapy is excessive and requires revision of patient selection criteria for this type of treatment $[6,30,31]$. Moreover, ASCO lists the reduction of chemotherapy overuse in patients with poor ECOG-PS as one of the top five priorities to improve patient care and reduce health care costs [6].

Valuable efforts have been made in an attempt to determine prognostic markers that can help identify the patients with very short life expectancy, and therefore, not likely to benefit from PC [32]. In our study, hyperbilirubinemia was the strongest prognostic factor associated with 30-day mortality in the multivariable analysis. This 
finding is likely due to the correlation between increased bilirubin and liver failure, and because half of our patients had a primary gastrointestinal tumor, which commonly metastasizes to the liver. Also, ECOG-PS 3-4 and hypercalcemia were correlated with shorter survival.

Another retrospective study conducted at ICESP with predominantly outpatients reinforce that ECOG-PS 3-4 was a predictor of 90-mortality. In contrast to our results, Caires-Lima et al. cohort found that elevated creatinine was a statistically significant predictor factor of early mortality [33]. Validated prognostic tools were shown to predicted survival and can be useful in the evidence-based cancer treatment decision process [34]. Although this represents a promising approach, this strategy still requires prospective validation for general clinical use. More importantly, these prognostic markers still remain to be validated with more recent treatment approaches, such as tyrosine kinase inhibitors and immune checkpoint inhibitors, where treatment is usually much better tolerated and carries lower rates of grade 3-4 adverse events [35-37].

Our study has inherent limitations due to its retrospective nature. Other potential limitations are: (i) the lack of a control group; (ii) there was no systematic report of treatment related toxicities precluding the data collection; (iii) we were not able to obtain information related to quality of life and radiologic response; (iv) our study included a large variety of cancer types, with heterogeneous prognoses and a high proportion of stomach and pancreatic/biliary tumors, which could be associated with poor prognosis and may have contributed to a worse outcome in the population; and (v) unmeasured confounding factors (e.g. disease burden and high volume of metastatic disease) are also a potential source of bias.

On the other hand, the strengths of our cohort include: (i) its robust sample size, which, to the best of our knowledge, is the largest single-center cohort of patients with advanced cancer and poor performance status who started PC during hospitalization; (ii) our broad inclusion criteria allow a great representation of this population and a proper evaluation of risk factors associated with early mortality; (iii) we analyzed real-world data, which is potentially generalizable to other public academic institutions; (iv) the assistance for hospitalized patients with advanced malignancies may be influenced by local culture; and (v) we provide data on the oncologic care for this Latin America population, which is scarcely represented in previous studies.

Based on our results, we suggest that physicians should be aware of the outcomes of inpatient PC in this scenario and the factors associated with early mortality to allow better decision-making. Importantly, this information should also be shared with patients and their families to allow more informed decisions.
A multicenter and international exchange of experiences would be helpful in order to build a collaborative line of work [38], concentrating efforts to assess the real magnitude of the clinical benefit of PC and to increase the cost-effectiveness of active cancer treatments, especially in the limited resources scenario of developing countries [39].

\section{Conclusions}

Our study showed that patients with advanced solid tumors and poor performance status treated with inpatient PC had a poor prognosis and short survival. PC in the inpatient setting is associated with aggressive end-of-life care, including ICU admission. Elevated bilirubin, hypercalcemia, and ECOG-PS 3-4 are associated with 30-day mortality and may be used to aid in treatment decisions for this patient population.

\section{Abbreviations \\ ALT: alanine aminotransferase; ASCO: American Society of Clinical Oncology; AST: aspartate aminotransferase; Bb: total bilirubin; BSC: best supportive of care; CNS: central nervous system; Cr: creatinine; ECOG-PS: Eastern cooperative oncology group performance status; Hb: hemoglobin; ICESP: Instituto do Câncer do Estado de São Paulo; ICU: intensive care unit; LFT: liver function tests; OR: Odds Ratio; PC: Palliative chemotherapy}

\section{Acknowledgements}

Daniel Fernandes Saragiotto: We acknowledge the outstanding mentoring and professional support of Dr. Saragiotto to all authors of the manuscript.

\section{Funding \\ The authors declare that they have no funding.}

Availability of data and materials

the datasets used and/or analysed during the current study are available from the corresponding author on reasonable request.

\section{Authors' contributions}

VFV, MVN and RPR participated in the concept and design of the study. VFV, RRCCB, GA participated in the data collection. VFV, RRCCB, GA, MVN, RPR participated in the data analysis. VFV, RRCCB, GA, MVN, RPR drafted, reviewed, and approved the final manuscript.

Ethics approval and consent to participate

approved by "Comitê de ética em Pesquisa FMUSP" on July, 112016.

Consent for publication

not applicable.

Competing interests

The authors declare that they have no competing interests.

\section{Publisher's Note}

Springer Nature remains neutral with regard to jurisdictional claims in published maps and institutional affiliations.

\section{Author details}

${ }^{1}$ Medical Oncology Department, Instituto do Cancer do Estado de São Paulo (ICESP), Avenida Dr. Arnaldo, 251, Cerqueira César, São Paulo 01246-000, Brazil. 'Department of Thoracic/Head and Neck Medical Oncology, The University of Texas, MD Anderson Cancer Center, 1515 Holcombe Blvd, Unit 432, Houston, TX 77030, USA. ${ }^{3}$ Department of Clinical Oncology, AC Camargo Cancer Center, R. Prof. Antônio Prudente, 211 - Liberdade, São Paulo, SP 01509-010, Brazil. 
Received: 17 December 2018 Accepted: 9 May 2019

Published online: 20 May 2019

\section{References}

1. Oken MM, Creech RH, Tormey DC, Horton J, Davis TE, McFadden ET, et al. Toxicity and response criteria of the eastern cooperative oncology group. Am J Clin Oncol. 1982;5(6):649-55.

2. DeVita VT Jr, Chu E. A history of Cancer chemotherapy. Cancer Res. 2008; 68(21):8643-53.

3. Chan WL, Lam KO, Siu WK, Yuen KK. Chemotherapy at end-of-life: an integration of oncology and palliative team. Support Care Cancer. 2016; 24(3):1421-7.

4. Roeland EJ, LeBlanc TW. Palliative chemotherapy: oxymoron or misunderstanding? BMC Palliat Care. 2016;15(1):33.

5. Reljic T, et al. Treatment targeted at underying disease versus palliative care in terminally ill patients: a systematic review. BMJ Open. 2017;7:e014661.

6. Schnipper LE, Smith TJ, Raghavan D, Blayney DW, Ganz PA, Mulvey TM, Wollins DS. American Society of Clinical Oncology identifies five key opportunities to improve care and reduce costs: the top five list for oncology. J Clin Oncol. 2012;30(14):1715-24.

7. Prigerson HG, Bao Y, Shah MA, Paulk ME, LeBlanc TW, Schneider BJ, Garrido MM, Reid MC, Berlin DA, Adelson KB, et al. Chemotherapy Use, Performance Status, and Quality of Life at the End of Life. JAMA Oncol. 2015;1(6):778-84.

8. Crosara Teixeira M, Marques DF, Ferrari AC, Alves MF, Alex AK, Sabbaga J, Hoff PM, Riechelmann RP. The effects of palliative chemotherapy in metastatic colorectal cancer patients with an ECOG performance status of 3 and 4. Clin Colorectal Cancer. 2015;14(1):52-7.

9. Ali M, Cripps MC, Balchin K, Spencer J, Wheatley-Price P. Palliative inpatient chemotherapy: clinical benefit or harm? J Clin Oncol. 2012;30(15_suppl):e19527.

10. Rocque GB, Barnett AE, Illig LC, Eickhoff JC, Bailey HH, Campbell TC, Stewart JA, Cleary JF. Inpatient hospitalization of oncology patients: are we missing an opportunity for end-of-life care? J Oncol Pract. 2013;9(1):51-4.

11. Rocha LS, Riechelmann RP. Treatment of patients with metastatic colorectal cancer and poor performance status: current evidence and challenges. Clinics. 2018;73(suppl 1):e542s.

12. Lee HS, Chun KH, Moon D, Lee S, Lee S. Trends in receiving chemotherapy for advanced cancer patients at the end of life. BMC Palliat Care. 2015:14(1):4.

13. Soto-Perez-de-Celis E, Chavarri-Guerra Y, Pastrana T, Ruiz-Mendoza R, Bukowski A, Goss PE. End-of-life Care in Latin America. J Glob Oncol. 2017;3(3):261-70.

14. Charlson ME, Pompei $P$, Ales KL, MacKenzie CR. A new method of classifying prognostic comorbidity in longitudinal studies: development and validation. J Chronic Dis. 1987:40(5):373-83.

15. Schouwenburg MG, Jochems A, Leeneman B, Franken MG, Van Den Eertwegh AJ, Haanen JB, Van Zeijl MC, Aarts MJ, Van Akkooi AC, Van Den Berkmortel FW, Blokx WA. Vemurafenib in BRAF-mutant metastatic melanoma patients in real-world clinical practice: prognostic factors associated with clinical outcomes. Melanoma Res. 2018;28(4):326-32.

16. Harano K, Lei X, Gonzalez-Angulo AM, Murthy RK, Valero V, Mittendorf EA, Ueno NT, Hortobagyi GN, Chavez-MacGregor M. Clinicopathological and surgical factors associated with long-term survival in patients with HER2positive metastatic breast cancer. Breast Cancer Res Treat. 2016;59(2):367-74

17. Murad AM, Santiago FF, Petroianu A, Rocha PR, Rodrigues MA, Rausch M. Modified therapy with 5-fluorouracil, doxorubicin, and methotrexate in advanced gastric cancer. Cancer. 1993;72(1):37-41.

18. Cunningham D, Glimelius B. A phase III study of irinotecan (CPT-11) versus best supportive care in patients with metastatic colorectal cancer who have failed 5 fluorouracil therapy. V301 study group. Semin Oncol. 1999;26(1 Suppl 5):6-12.

19. Shepherd FA, Dancey J, Ramlau R, Mattson K, Gralla R, O'Rourke M, Levitan $N$, Gressot L, Vincent M, Burkes $R$, et al. Prospective randomized trial of docetaxel versus best supportive care in patients with non-small-cell lung cancer previously treated with platinum-based chemotherapy. J Clin Oncol. 2000;18(10):2095-103.

20. Kawaguchi T, Takada M, Kubo A, Matsumura A, Fukai S, Tamura A, Saito R, Maruyama Y, Kawahara M, Ignatius Ou SH. Performance status and smoking status are independent favorable prognostic factors for survival in non-small cell lung cancer: a comprehensive analysis of 26,957 patients with NSCLC. J Thorac Oncol. 2010;5(5):620-30.

21. Sánchez-Muñoz A, Pérez-Ruiz E, Sáez MI, Trigo JM, Galindo MM, Manzaneque L, Jiménez B, Muros B, Alba E. Limited impact of palliative chemotherapy on survival in advanced solid tumours in patients with poor performance status. Clin Transl Oncol. 2011;13(6):426-9.
22. Wheatley-Price P, Ali M, Balchin K, Spencer J, Fitzgibbon E, Cripps C. The role of palliative chemotherapy in hospitalized patients. Curr Oncol. 2014;21(4):187-92.

23. Matsuyama R, Reddy S, Smith TJ. Why do patients choose chemotherapy near the end of life? A review of the perspective of those facing death from cancer. J Clin Oncol. 2006;24(21):3490-6.

24. Earle CC, Neville BA, Landrum MB, Ayanian JZ, Block SD, Weeks JC. Trends in the aggressiveness of Cancer care near the end of life. J Clin Oncol. 2004;22:315-21.

25. Wright AA, Zhang B, Keating NL, Weeks JC, Prigerson HG. Associations between palliative chemotherapy and adult cancer patients' end of life care and place of death: prospective cohort study. Bmj. 2014;348:g1219.

26. Cheon S, Agarwal A, Popovic M, Milakovic M, Lam M, Fu W, DiGiovanni J, Lam H, Lechner B, Pulenzas N, et al. The accuracy of clinicians' predictions of survival in advanced cancer: a review. Ann Palliat Med. 2016;5(1):22-9.

27. Su C, Zhou F, Shen J, Zhao J, O'Brien M. Treatment of elderly patients or patients who are performance status 2 (PS2) with advanced non-small cell lung Cancer without epidermal growth factor receptor (EGFR) mutations and anaplastic lymphoma kinase (ALK) translocations - still a daily challenge. Eur J Cancer. 2017:83:266-78.

28. Rochigneux P, Raoul JL, Beaussant Y, Aubry R, Goldwasser F, Tournigand C, Morin L. Use of chemotherapy near the end of life: what factors matter. Ann Oncol. 2017;28(4):809-17.

29. Ferrell BR, Temel JS, Temin S, Alesi ER, Balboni TA, Basch EM, Firn Jl, Paice JA, Peppercorn JM, Phillips T, et al. Integration of Palliative Care Into Standard Oncology Care: American Society of Clinical Oncology Clinical Practice Guideline Update. J Clin Oncol. 2017;35(1):96-112.

30. Braga S. Why do our patients get chemotherapy until the end of life? Ann Oncol. 2011;22(11):2345-8.

31. Emanuel EJ, Young-Xu Y, Levinsky NG, Gazelle G, Saynina O, Ash AS. Chemotherapy use among Medicare beneficiaries at the end of life. Ann Intern Med. 2003:138:639-43.

32. Hashimoto K, Yonemori K, Katsumata N, Hotchi M, Kouno T, Shimizu C, Tamura K, Ando M, Takeuchi M, Fujiwara Y. Factors that affect the duration of the interval between the completion of palliative chemotherapy and death. Oncologist. 2009;14(7):752-9.

33. Caires-Lima R, Cayres K, Protásio B, Caires I, Andrade J, Rocha L, Takahashi TK, Hoff PM, de Castro G, Mak MP. Palliative chemotherapy outcomes in patients with ECOG-PS higher than 1. Ecancermedicalscience. 2018;12:831.

34. Simmons CPL, McMillan DC, McWilliams K, Sande TA, Fearon KC, Tuck S, Fallon MT, Laird BJ. Prognostic Tools in Patients With Advanced Cancer: A Systematic Review. J Pain Symptom Manag. 2017;53(5):962-970.e910.

35. Pembrolizumab in patients with non-small cell lung Cancer and a performance status 2 (PeePS2) [https:/clinicaltrials.gov/ct2/show/NCT02733159].

36. A study of Atezolizumab compared with chemotherapy in treatment Naïve participants with locally advanced or recurrent or metastatic non-small cell lung Cancer who are deemed unsuitable for platinum-containing therapy (IPSOS) [https://clinicaltrials.gov/ct2/show/NCT03191786].

37. Matsuo N, Sekine A, Kato T, Hosoda C, Ito H, Baba T, Umeda S, Iwasawa T, Okudela K, Ogura T. Promising Effect of Crizotinib on Anaplastic Lymphoma Kinase (ALK)-Positive Non-Small Cell Lung Cancer in an Elderly Patient with a Poor Performance Status: A Case Report and Literature Review. Intern Med. 2016;55(5):507-9.

38. Valdivieso M, Corn BW, Dancey JE, Wickerham DL, Horvath LE, Perez EA, Urton A, Cronin WM, Field E, Lackey E, et al. The Globalization of Cooperative Groups. Semin Oncol. 2015;42(5):693-712.

39. Grössmann N, Del Paggio JC, Wolf S, Sullivan R, Booth CM, Rosian K, Emprechtinger $\mathrm{R}$, Wild $\mathrm{C}$. Five years of EMA-approved systemic cancer therapies for solid tumours - a comparison of two thresholds for meaningful clinical benefit. Eur J Cancer. 2017;82:66-71.

\section{Ready to submit your research? Choose BMC and benefit from:}

- fast, convenient online submission

- thorough peer review by experienced researchers in your field

- rapid publication on acceptance

- support for research data, including large and complex data types

- gold Open Access which fosters wider collaboration and increased citations

- maximum visibility for your research: over $100 \mathrm{M}$ website views per year

At $\mathrm{BMC}$, research is always in progress.

Learn more biomedcentral.com/submissions 